\title{
HOFFMANNIA STEPHANIAE (RUBIACEAE), UNA NUEVA ESPECIE DE COSTA RICA
}

\author{
Luis GonzÁlez Arce ${ }^{1} \&$ Luis Poveda Álvarez ${ }^{2}$ \\ ${ }^{1}$ Instituto Nacional de Biodiversidad (INBio), apdo. 22-3100, Santo Domingo, Heredia, Costa Rica \\ lgonzal@inbio.ac.cr \\ ${ }^{2}$ Herbario Juvenal Valerio (JVR), Universidad Nacional, apdo. 86-3000, Heredia, Costa Rica \\ lpoveda@una.ac.cr
}

\begin{abstract}
A new species of Hoffmannia (Rubiaceae) restricted to the La Cangreja National Park in Puriscal, Costa Rica, is described and illustrated in this paper. Compared to the rest of the species in the neotropical zone, Hoffmannia stephaniae is distinguished by the subsessile and linear leaves. In addition, the underside of the leaf blade has minute white points (stomata) and minute and numerous lines of raphides.

Resumen. Se describe e ilustra una nueva especie de Hoffmannia (Rubiaceae) que habita en el Parque Nacional La Cangreja, Puriscal, Costa Rica. Hoffmannia stephaniae es distintiva por sus hojas subsésiles y lineares. Además, el envés de la lámina foliar tiene diminutos puntos blancos (estomas) y numerosas y diminutas líneas de rafidios..
\end{abstract}

Palabras Clave / KeY words: Rubiaceae, Hoffmannia stephaniae, Costa Rica

Hoffmannia Sw. es un género compuesto por hierbas y arbustos con alrededor de 150 especies distribuidas desde México y Las Antillas hasta Sudamérica (Taylor, en preparación). Burger \& Taylor (1997) registran 26 especies de este género en Costa Rica. Taylor (loc. cit.) señala que algunas especies poseen domacios o vesículas con hormigas. Las inflorescencias son axilares, glomeruladas hasta cimosas y abiertas, frecuentemente cincinoides, la mayoría con cuatro flores de corola infundibuliforme a rotácea y ovario con dos (3-4) lóculos. Los frutos son bayas suculentas, elipsoides.

Hoffmannia stephaniae L.A. González \& Poveda, sp. nova

TIPO: Costa Rica. San José: Puriscal, Chires, Parque Nacional La Cangreja, 09॰43'25"N, $84^{\circ} 22^{\prime} 41^{\prime \prime W}$, ca. 1000 m, 27 jun. 1996 (fl), L. González et al. 360 (holotipo: INB, isotipos: CR, $\mathrm{MO})$.

FIG. 1.

Ab omnibus speciebus generis Hoffmanniae foliis linearibus, subsessilibus, infra minute albo-punctatis differt.

Hierba erecta de $1 \mathrm{~m}$ de altura. Extremos distales de las ramitas con gran número de diminutas líneas de rafidios. Estípulas 1,0-1,5 $\mathrm{mm}$ de longitud, triangulares, glabras y caducas. Hojas $5-13.5 \times 0,5-1,5$ $\mathrm{cm}$, opuestas; pecíolos de 1,0-1,8 × 1,5-3,0 mm, aplanados adaxialmente, con numerosas líneas de rafidios. Lámina foliar linear y decurrente hasta la base, ésta cuneada, ápice acuminado, margen de la lámina entero, haz glabro, pardo-negruzco al secar, nervio central prominente y pardo-rojizo, nervios secundarios poco evidentes, unidos cerca del margen de la lámina, envés glabro, con diminutos puntos blancuzcos (estomas), además con numerosas y diminutas líneas de rafidios en el nervio central. Inflorescencia un dicasio simple, axilar, solitario, a veces yugado, pedúnculos de 1,5-3,0 $\mathrm{cm}$ de longitud, glabros; flores bisexuales, 4,0-9,0 mm de longitud, pedicelos de 2,0-5,5 $\mathrm{mm}$ de longitud, con diminutas bracteolas en el punto de unión con el pedúnculo, hipanto con hasta 7 costillas longitudinales; cáliz verde, sépalos 4, de 1,5-2,0 mm de longitud, glabros y con diminutas líneas de rafidios; corola infundibuliforme, de $4 \mathrm{~mm}$ de longitud, de color verdoso con manchas o puntos marrón, tubo de $2 \mathrm{~mm}$ de longitud, lóbulos de los pétalos 1,4-1,6 × 3,0-4,0 mm, imbricados, glabros y con diminutas líneas de rafidios; estambres 4, filamentos de $0,2 \mathrm{~mm}$ de longitud, glabros, insertos cerca de la base de los lóbulos de la 


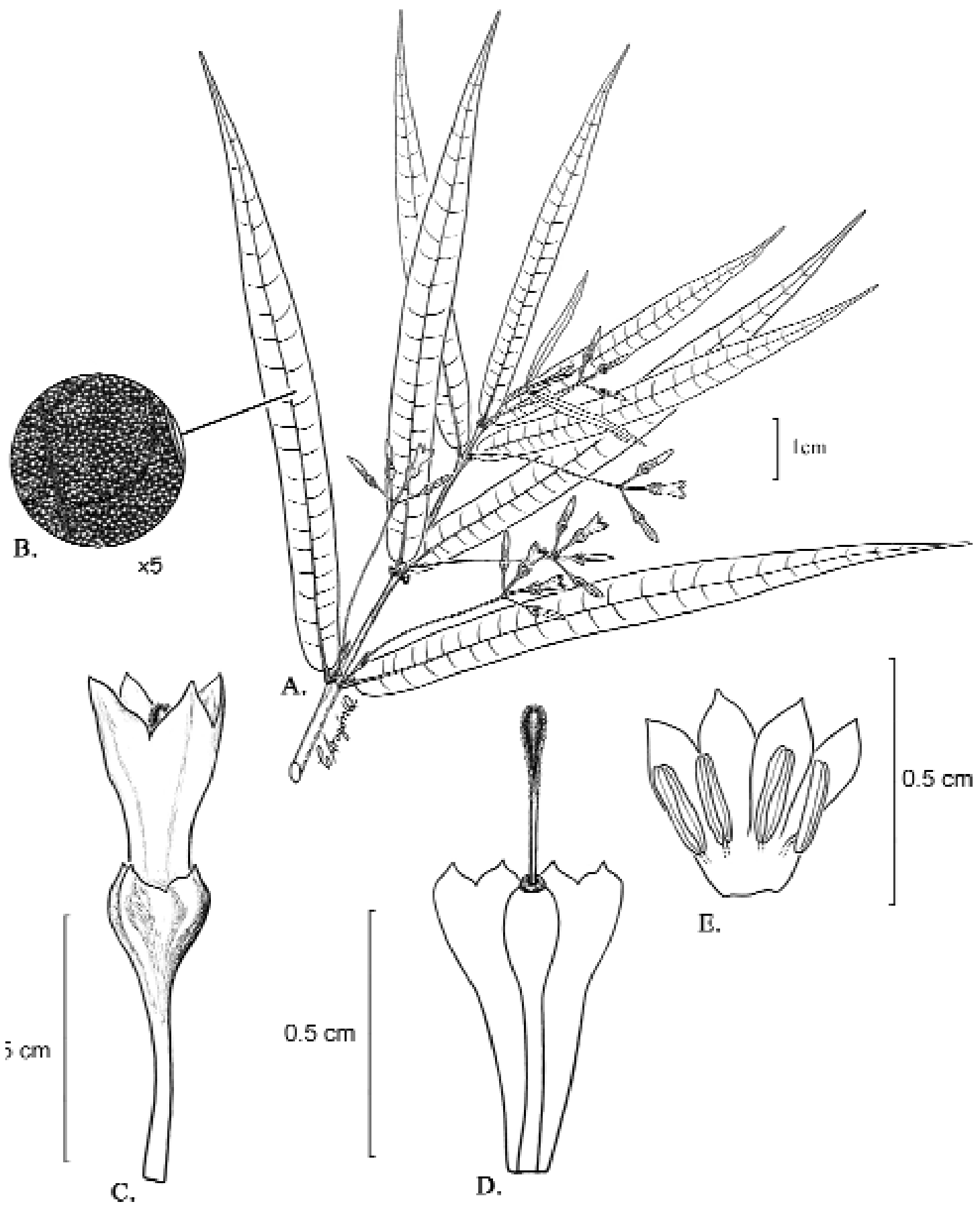

Fig. 1. Hoffmannia stephaniae L.A. González \& Poveda. A - Ramita florida. B - Detalle de los estomas (puntos blancuzcos) en el envés de la hoja (x 5). C - Flor íntegra. D - Detalle de la flor que muestra el nectario anular en la base del estilo. E - Estambres. Testigo de la ilustración: L. González et al. 360 (INB). 
corola, anteras ca. 2,5 mm de longitud, lineares, tecas 2, con dehiscencia longitudinal; ovario glabro, estilo ca. $5 \mathrm{~mm}$ de longitud, con un nectario anular pardo oscuro en la base. Frutos desconocidos.

DistribuCIÓN Y HÁBITAT. Hoffmannia stephaniae habita en los bosques húmedos del Parque Nacional La Cangreja, Puriscal, entre 700 y 1000 m de altitud.

Etimología. La nueva especie se dedica a Stephanía González Murillo, hija de uno de los autores.

Hoffmannia stephaniae es una especie distinguible por sus hojas lineares de $1,5 \mathrm{~cm}$ o menos de ancho y hasta $3,5 \mathrm{~cm}$ de longitud; la planta es completamente glabra en todas sus partes y el hipanto muestra hasta siete costillas longitudinales.
Agradecimientos. Los autores deseamos agradecer a Claudia Aragón por las ilustraciones, a José González por la revisión del manuscrito y a Carlos O. Morales por la traducción al latín.

\section{LITERATURA CITADA}

Burger, W. \& Taylor, C. 1997. Rubiaceae. In: Burger, W.C. (ed.). Flora Costaricensis. Fieldiana, Bot. n. s. 33: 166-179.

Taylor, C. (en preparación). Rubiaceae. In: Hammel, B.E., Zamora, N. \& Grayum, M.H. (eds.). Manual de Plantas de Costa Rica. St. Louis, Missouri Bot. Gard. / Inst. Nac. de Biodiversidad. 